\title{
Improving Transfer of Parkinson's Disease Patients - Sit-to-Stand Motion Assistance
}

\author{
Yoshiyuki Takahashi ${ }^{1}$, Osamu Nitta ${ }^{2}$ and Takashi Komeda ${ }^{3}$ \\ ${ }^{1}$ Toyo University, \\ ${ }^{2}$ Tokyo Metropolitan University, \\ ${ }^{3}$ Shibaura Institute of Technology, \\ Japan
}

\section{Introduction}

In many areas of the world, population aging is steadily increasing. Japan became an aged society in 1995 and the numbers of Japanese citizens aged 65 years and above (elderly) continues to increase. In 2010, the percentage of elderly people in Japan reached $23.1 \%$. In such a "super-aged" society, health maintenance, along with the prevention and treatment of diseases, are important long-term social care issues affecting elderly people.

Because the incidence of Parkinson's disease (PD) onset increases among persons over 50 years of age, it can be considered an age-related ailment, and there were approximately 145,000 confirmed PD patients in Japan at the time of this research. PD is caused by the death of dopamine-containing cells in substantia nigra of the brain. Common symptoms of PD are tremors, muscle stiffness, slow movement and poor balance, as well as other movement-related problems. When walking and during sit-to-stand motions, persons afflicted with such symptoms face increased risks from falls and subsequent injuries.

Ensuring efficient and safe transfer motions helps ensure self-reliant lifestyles, especially among elderly and physically disabled people, including PD patients. Transfer motions are among the basic activities of daily life. To help such persons, there are a number of commercially available sit-to-stand assistance devices on the market today, most of which assist users in rising from chairs by means of a lift seat that reduces the load on their lower limbs. However, from the viewpoint of maintaining lower muscle strength, excessive assistance is undesirable. Because of this, we have developed an effective sit-to-stand assistance system that provides the minimum assistance necessary.

In this paper, an outline of our developed sit-to-stand assistance system is introduced and experiments with this system involving individuals diagnosed with PD are described. It was found that the proposed system effectively permitted individuals to rise from a seated position.

\section{Research background}

There are numerous different tools and devices designed to assist transfer maneuvers. Most commonly, handrails are provided for individuals who have problems standing up and walking. However, handrails are difficult to adjust once installed. This can pose difficulties 
in situations where an individual's physical abilities change over a short period of time due to age and/or disease, because such changes often require that the position of an installed handrail be modified.

Such modifications often require reconstruction of the facilities. The typical position of a handrail that meets industrial standards e.g. Japanese Industrial Standard (JIS) is not suitable for all people because of differences in body size and physical abilities. Accordingly, the primary purpose of this research was the development of a moveable handrail system that provides sit-to-stand assistance that can be personalized to individual users.

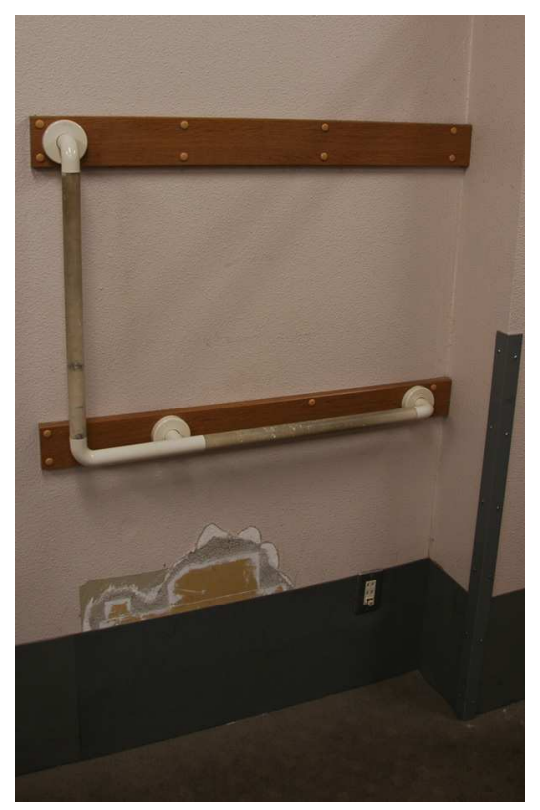

Fig. 1. Typical handrail installation

Previous handrail studies focused primarily on finding generalized heights and shapes, and no reports discussing active handrails for stand-up assistance were found. However, a number of active stand-up assistance devices have been developed. These include the Rehabilitation Robot Cell for Multimodal Stand-Up Motion Augmentation and the StandUp Motion Assistance System. Furthermore, the following devices are already available commercially: a seat lift chair, a lifting cushion, and a toilet seat lift. Such devices, which are not aimed at rehabilitation efforts, assist users in getting up from chairs by means of a lift seat that reduces the load on their lower limbs.

However, from the viewpoint of maintaining the lower muscle strength of a patient, excessive assistance is undesirable. Based on observations of the standing motions of large numbers of PD patients and elderly persons, it is clear that a significant percentage of such individuals would be able to stand up, despite poor motor function, if the transfer motion could be assisted in some ways. Therefore, we attempted to develop an effective sit-to-stand assistance system that provides the minimum degree of assistance necessary. 


\section{Sit-to-stand motion assistance system}

Our prototype sit-to-stand assistance system was designed for elderly and disabled persons, including PD patients, who find it difficult to stand up from a sitting position. Figure 2 shows an overview of this sit-to-stand assistance system, which consists of two $650 \mathrm{~mm}$ stroke AC servo motor driven linear actuators combined in a square configuration and a handrail installed at the intersection of these actuators. When a user begins to stand from a seated position on a chair, the handrail moves to lead his or her motions. A personal computer was used to control the handrail movements, which was designed to move a 490 $\mathrm{N}$ load at a maximum velocity of $125 \mathrm{~mm} / \mathrm{s}$.

Figure 3 shows the system diagram. A six-axis force sensor (100M40A, JR3, Inc., California, USA) was attached to the base of the handrail. Figure 4 shows the six-axis force sensor coordinate system. The control program of the system calculates the trajectory of the handrail, and the force exerted on the handrail can be used to actuate the handrail movement. The direction and the actuating speed can be set on the control panel.

In our experiment, two force detection plates were positioned under the feet of the users, as shown in Figure 5. Each plate was $400 \mathrm{~mm}$ in length and $300 \mathrm{~mm}$ wide. The plates were designed to detect the floor reaction force exerted as the subject was standing up. A maximum force of $1500 \mathrm{~N}$ could be measured at a resolution lower than $2.5 \mathrm{~N}$.

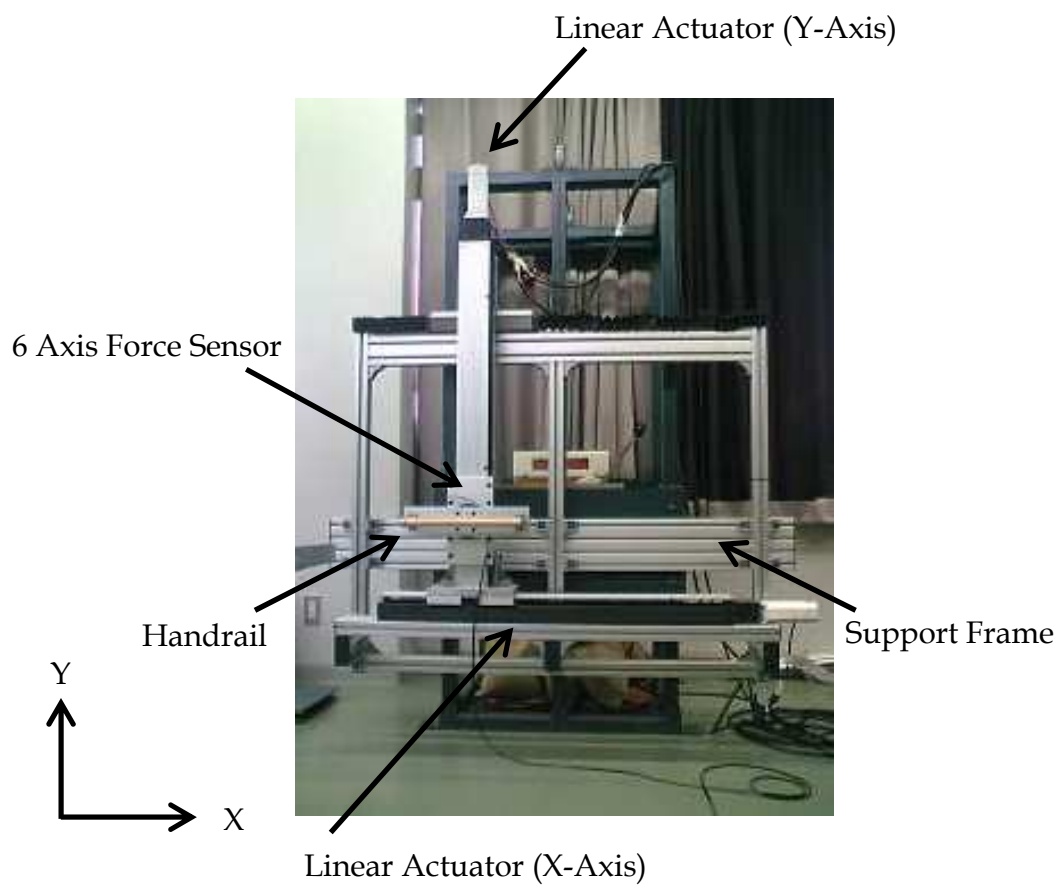

Fig. 2. Experimental sit-to-stand assistance system 


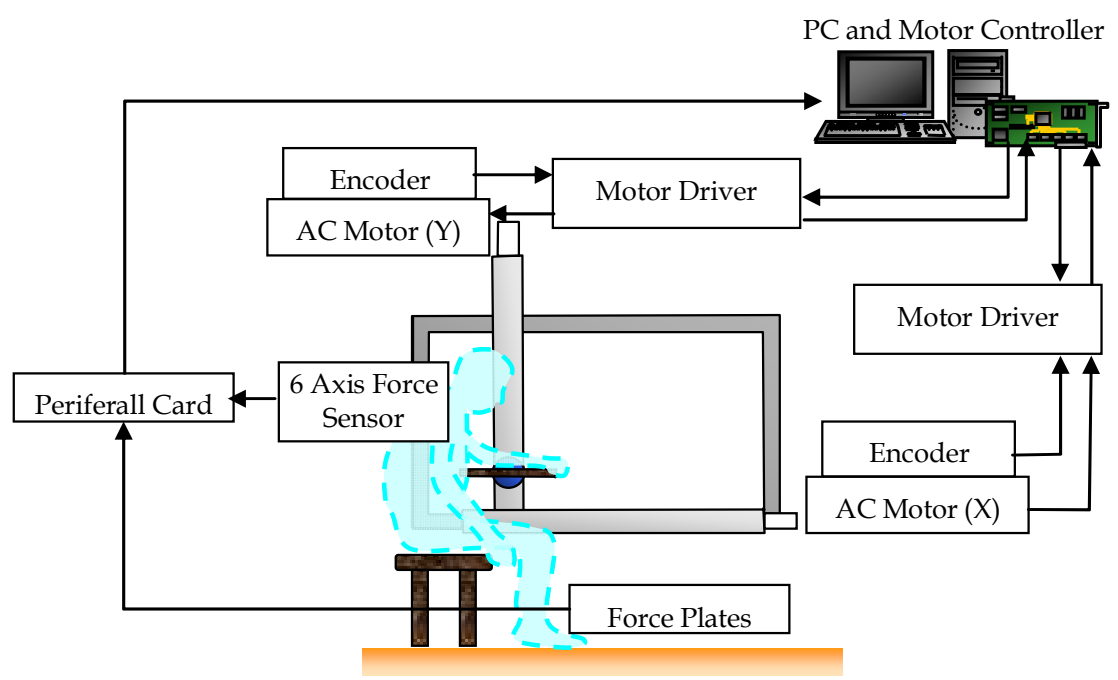

Fig. 3. Overview of the sit-to-stand motion assistance system

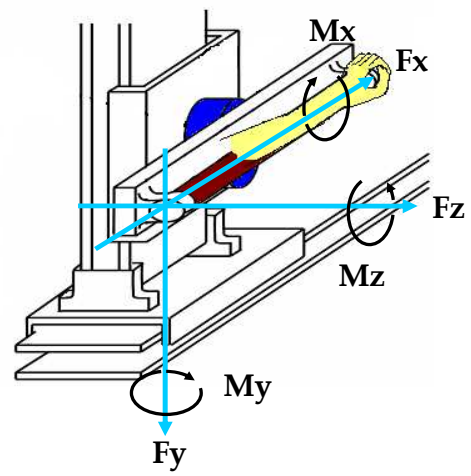

Fig. 4. 6 Axis force sensor coordinate system

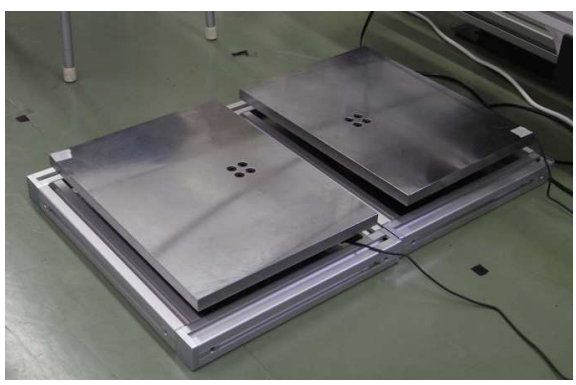

Fig. 5. Force detection plates for measuring feet pressure 


\section{Handrail motion}

\subsection{Concept of the sit-to-stand motion assistant strategy}

People normally utilize two different strategies when executing a sit-to-stand maneuver. One is a sudden, rapid torso bend-and-straighten motion that generates and utilizes inertia to propel the person to a standing position. The other involves moving the person's center of gravity (CG) position slowly forward, balancing on the legs, and then straightening into the standing position. Normal healthy people can flex their torsos very rapidly, so they do not need to make excessive motions. In contrast, elderly people with low muscle strength are unable to make rapid torso motions. As a result, they normally move their torso forward to shift their $C G$, and then straighten up using the muscle strength of their legs.

In case of PD patients, it is often difficult for such persons to flex their torsos forward and back quickly enough to execute the first method and (due to increased muscle tone) they lack the knee joint extension power and flexibility needed to rise to the standing position, which is necessary for the second method. Furthermore, since their CG position does not move forward sufficiently, it is easy for such persons to fall backwards, as shown in Figure 6 . Therefore, to assist such persons' sit-to-stand motions, the following method was considered to be effective. First, pulling their torso forward slowly until their CG positions moved onto their base of support and then leading their torsos upwards in a straight motion.

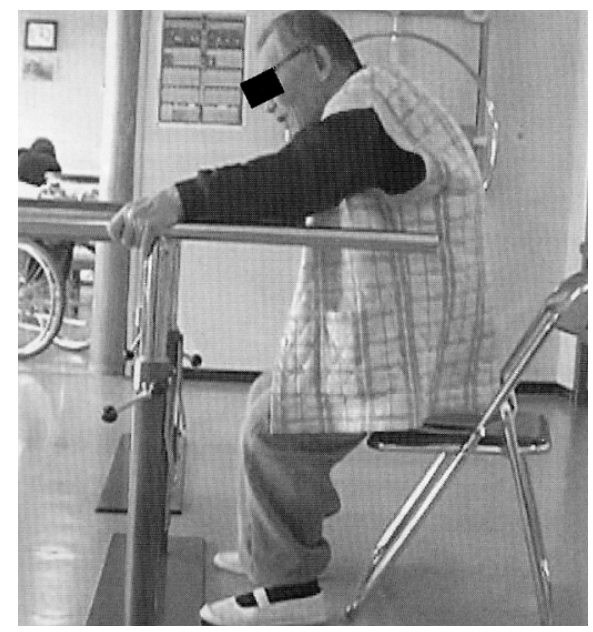

Fig. 6. Elderly PD patient standing up from a chair

\subsection{Design of the individualized handrail trajectory system}

In previous experiments, we examined three different handrail trajectories for PD patient sit-to-stand motion assistance. These included a horizontal motion, a diagonal motion and a curvature motion that was based on the shoulder motions of a normal healthy adult. Our examinations indicated that, in most cases, a trajectory based on the shoulder motion of a normal healthy individual in the process of standing up was effective for PD patient sit-to-stand motion assistance because it successfully assisted patients who were unable to stand using a fixed handrail. In these experiments, it was confirmed that the patient CG 
moved onto the base of support before the seat-lift and the handrail pulling force was decreased.

However, the curvature trajectory was not suitable for all PD patients. We then examined a fixed trajectory and determined that it would not be able to accommodate different user heights. Finally, we designed a new approach, which was to adjust the timing of the handrail motions using measurements of the force applied to the floor beneath the patient's feet in order to determine whether the CG had moved onto the base of support.

In this evolution, the handrail first moves slowly forward and downward to bend the patient's torso and shift his or her CG onto the base of support. Then, when the force under the patient's feet exceeds the preset threshold, the handrail begins moving upwards and slightly backwards to extend the patient's torso vertically. The original curvature trajectory was segmented and set to an approximate curve. Figure 7 shows a typical handrail trajectory and its formula.

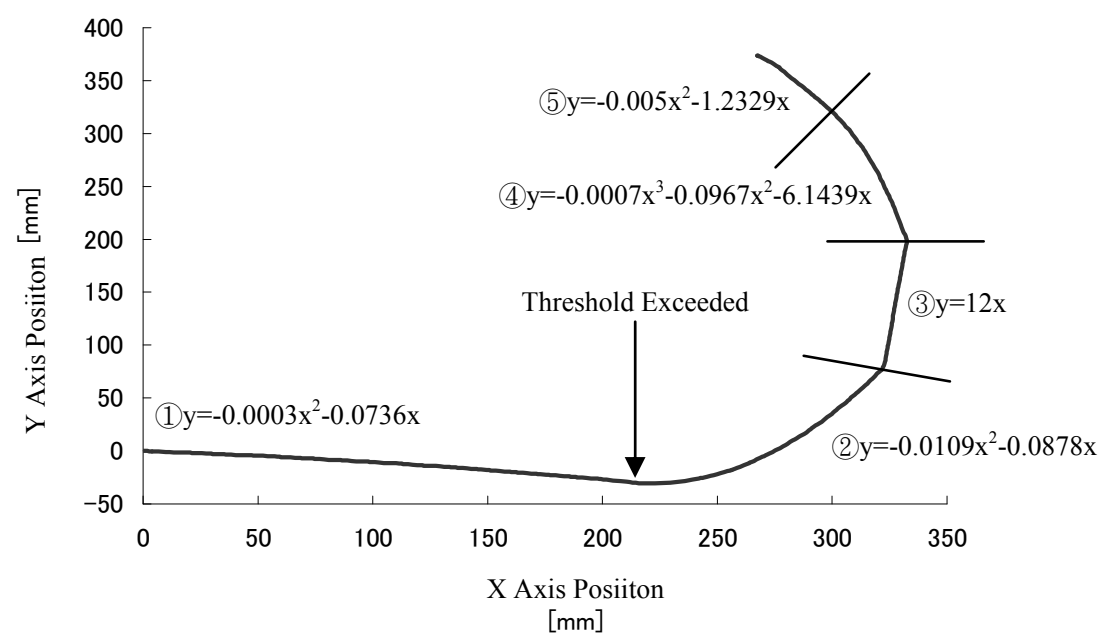

Fig. 7. Typical handrail trajectory

\section{Materials and methods}

The prototype sit-to-stand assistance system was designed and tested in conjunction with the handrail trajectory control program, and experiments were conducted to evaluate the sit-to-stand motion of PD patients as compared with normal healthy subjects.

\subsection{Subjects}

Two PD patients and two healthy adults (selected as the control subjects) participated as text subjects in this experiment. Both PD test subjects were diagnosed as Stage 4 patients based on the Hoehn and Yahr Scale. The mean age of the PD test subjects was 73.5 years (SD, 1.5 years). Their average weight was $48.5 \mathrm{~kg}$ (SD $5.5 \mathrm{~kg}$ ); average height was $1.60 \mathrm{~m}$ (SD $0.03 \mathrm{~m}$ ). Neither subject could stand up from a chair unassisted. The average weight of the control subjects was $70.5 \mathrm{~kg}(\mathrm{SD}, 1.5 \mathrm{~kg})$. The average height was $1.73 \mathrm{~m}$ (SD, $0.01 \mathrm{~m})$. Informed consent was obtained from all test subjects. 


\subsection{Tasks and protocols}

The initial posture of the subjects is shown in Figure 8. The $X$ axis of the coordinate system is horizontal and the $\mathrm{Y}$ axis is vertical. Test subjects were positioned on a height-adjustable stool with an initial lower limb posture as follows: hips were flexed at $90^{\circ}$ and knees were flexed at $80^{\circ}$. The height of the stool was set between approximately 370 and $390 \mathrm{~mm}$. The height of the stool and the posture of the test subject were selected to simulate the position of a user on a toilet seat, as set in the Japanese Industrial Standard. The handrail was set to fit initial upper limb posture: the elbow position was $110^{\circ}$.

The PD test subjects were asked to perform sit-to-stand motions from a stool using the proposed sit-to-stand assistance system. Figure 7 shows an example of the handrail trajectories. Here, it can be seen that the handrail moves forward ( $X$ axis) and then curves upward ( $Y$ axis). In this experiment, the reaction force exerted on the floor under the feet of the test subjects was used to switch the handrail motion direction. Three different levels of reaction force, equal to $50 \%, 70 \%$ and $80 \%$ of the test subjects' body weight were used as thresholds. Each subject was asked to perform the sit-to-stand motion two times.

\subsection{Measurements}

A total of 11 optical markers were placed on key points of the subjects (the head of the 5th metatarsal bone, the lateral malleoluses, knee joints, hip joints, shoulders, top of the head, elbow, and wrist) and on the edge of the handrail. The locations of the optical markers are shown in Figure 5. A Vicon motion analysis system (Vicon 370, Oxford Metrics, Ltd. Oxford, $\mathrm{UK}$ ) operating at a rate of $60 \mathrm{~Hz}$ was used to measure the various positions and calculate the posture of the subjects. Four floor-mounted force detection plates were used to measure the reaction force exerted on the chair and floor. The six-axis force sensor, operating at a rate of $30 \mathrm{~Hz}$, measured the force exerted on the handrail and the two floor mounted force detection plates were used to determine when to switch the handrail motion direction. The marker positions, along with the pressures applied to the handrail and force detection plates, were all measured simultaneously. The corrected data was low-pass filtered using a 7 $\mathrm{Hz}$ Butterworth filter.

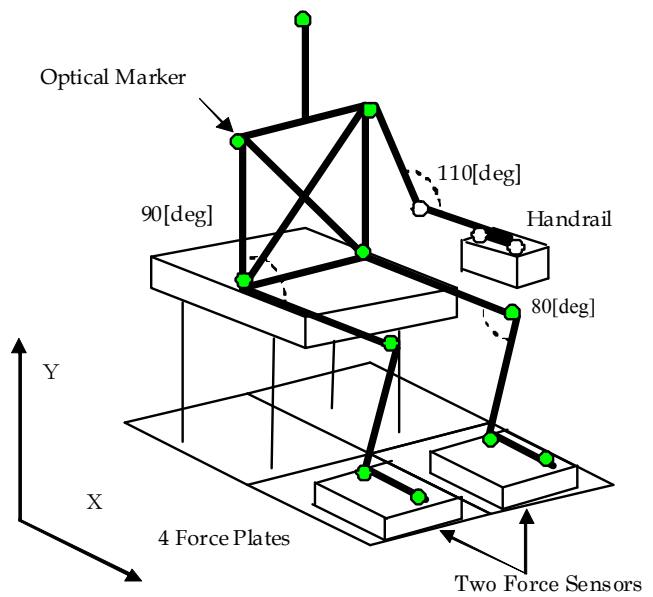

Fig. 8. Initial posture of the subject and the force sensor locations 
The position of the test subject's CG was calculated by the positions of the 11 optical markers. A rigid link model, which consisted of the feet, lower legs, thighs, torso and head of the test subject, was used. The values used for the moment of inertia and the center of mass of body parts were taken from a database of body part characteristics for Japanese elderly people.

The timing of the seat-off event was set at the point when Y-axis force on the floor mounted force plates became $0 \mathrm{~N}$. Figure 9 shows a PD test subject participating in the experiment.

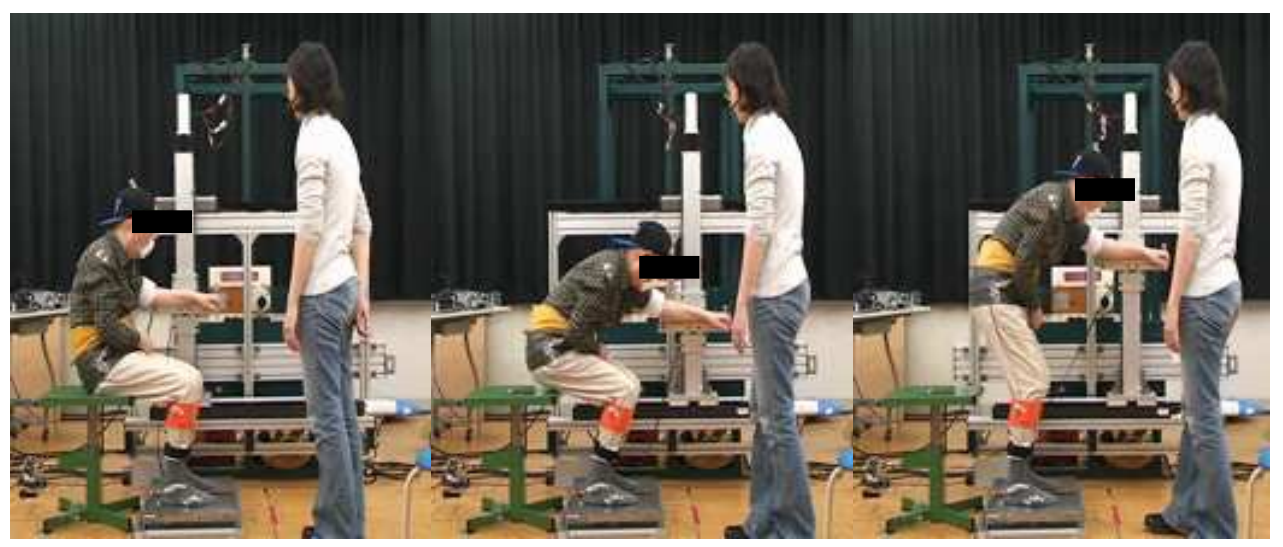

Fig. 9. PD test subject participating in the experiment

\section{Results}

\subsection{CG position}

Figure 10 shows examples of the handrail trajectories. The origin is set to the initial position of the handrail. Table 1 shows the average handrail positions that were moving direction switching position in $\mathrm{X}$ axis. The handrail trajectory was programmed to switch movement directions at certain points. Measurements equal to $50 \%, 70 \%$ and $80 \%$ of the test subject's body weight were set as thresholds. For the $80 \%$ threshold, the handrail was extended further forward than when the $50 \%$ and $70 \%$ threshold were set.

Figure 11 shows the CG trajectories. The $X$ and $Y$ axes positions were divided by the subject's body height and normalized. Table 2 shows the average CG positions when the seat-off point and maximum forward position occurred. The CG positions were then divided by the subject's foot length and normalized.

For healthy test subjects that did not use the handrail, the CGs were found to have moved forward and slightly down at first, following which, they moved upward in a curve. The seat-off position was designated at the point when the CG moved $10 \%$ of the test subject's foot length. At the 50\% threshold, the maximum forward position of the CG was $-18 \%$ of the test subject's foot length, at which point the PD test subjects were unable to stand. Therefore, it was considered likely that the CG had not moved onto the base of support. In the case of the $70 \%$ threshold, the subject could stand, however when the CG started to rise its movement distance was found to be less than that of a normal healthy test subject. At the $80 \%$ threshold, the test subject was able to stand smoothly and the CG trajectory was similar to that of a healthy test subject. The maximum recorded forward position of the CG was $54 \%$ of the test subject's foot length, which was roughly similar to that of a healthy test subject. 


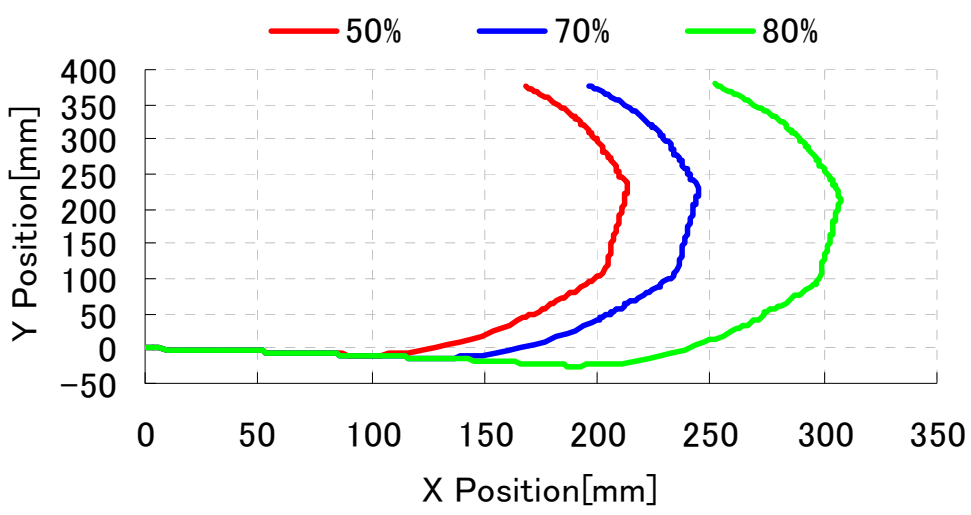

Fig. 10. Handrail trajectories

\begin{tabular}{c|c}
\hline Threshold (\% of body weight) & Handrail Position [mm] \\
\hline $50 \%$ & 92 \\
$70 \%$ & 232 \\
$80 \%$ & 272 \\
\hline
\end{tabular}

Table 1. Average handrail positions actuated by the handrail trajectory

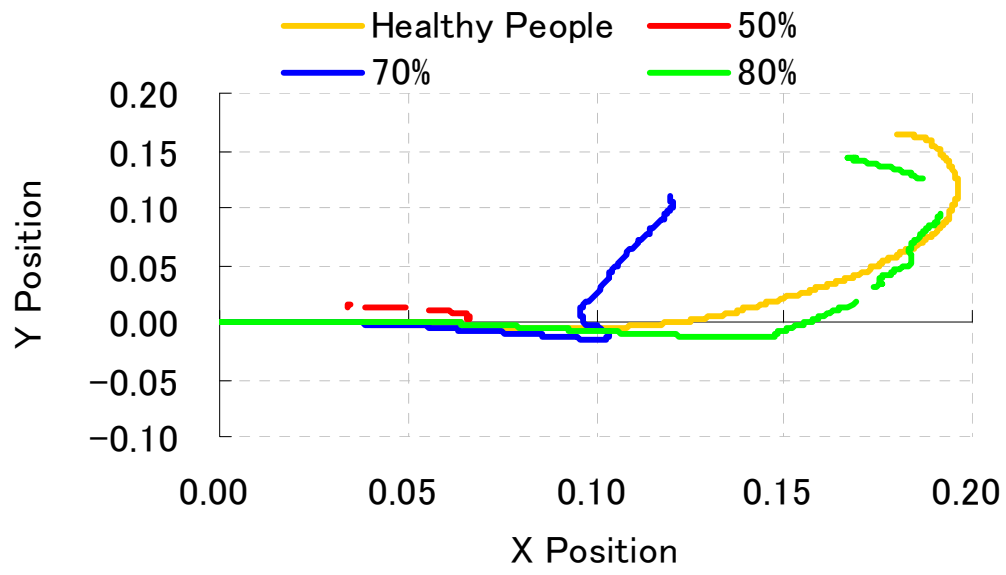

Fig. 11. CG trajectories

\begin{tabular}{c|c|c}
\hline Threshold (\% of body weight) & $\begin{array}{c}\text { Seat-off Position } \\
\text { [\% of foot length] }\end{array}$ & $\begin{array}{c}\text { Max. Forward Position } \\
\text { [\% of foot length] }\end{array}$ \\
\hline Control (Healty Subject) & 10 & 54 \\
$50 \%$ & - & -18 \\
$70 \%$ & 16 & 37 \\
$80 \%$ & 20 & 54 \\
\hline
\end{tabular}

Table 2. Maximum forward CG position 


\subsection{Torso and thigh angle}

Figure 12 shows the torso and thigh angles of the healthy test subjects. Figures 13 and 14 show the torso angle, thigh angle and $X$ axis position of the handrail for the PD subjects at the $70 \%$ and $80 \%$ thresholds. The horizontal axis indicates the timeline, which was divided by the total time and normalized. The origin of the torso angle is set on the horizontal line that extends through the hip joints. The origin of thigh angle is set on the horizontal line that extends through the knee joint. The initial position of the handrail is set as the origin point. For the healthy test subjects, thigh angles increased before seat-off occurred, after which the torso angles also increased. For the $70 \%$ and $80 \%$ thresholds, the torso angle increased after the handrail moved backward in the horizontal direction. In the case of the $80 \%$ threshold, the torso angle began increasing after seat-off occurred, at which time the handrail began moving backwards. This indicates that, in the case of $80 \%$ threshold, the test subject's body bent forward during the standing motion and the CG remained within the base of support. This motion assistance allowed the achievement of a stable sit-to-stand motion.

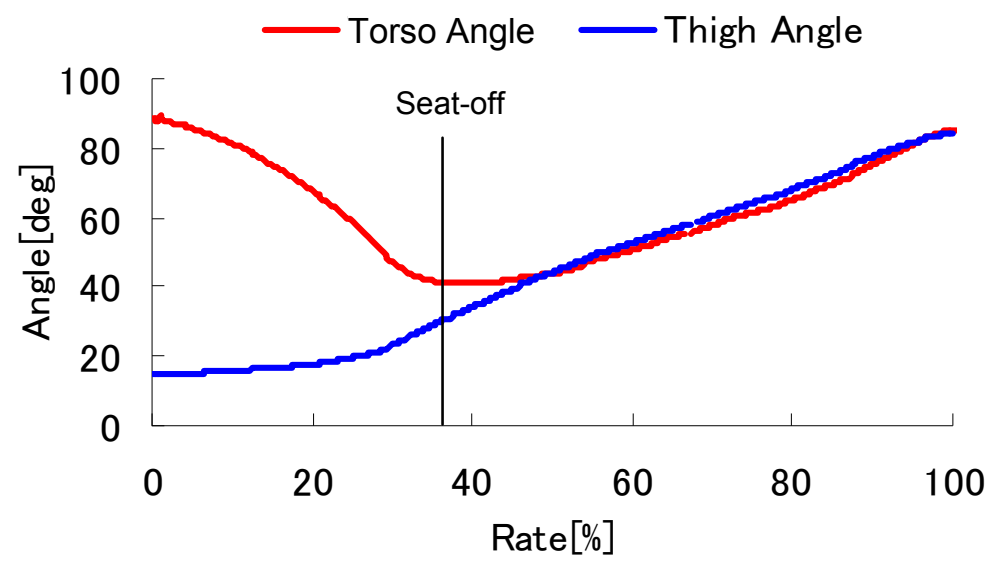

Fig. 12. Torso angle and thigh angle of a normal healthy subject

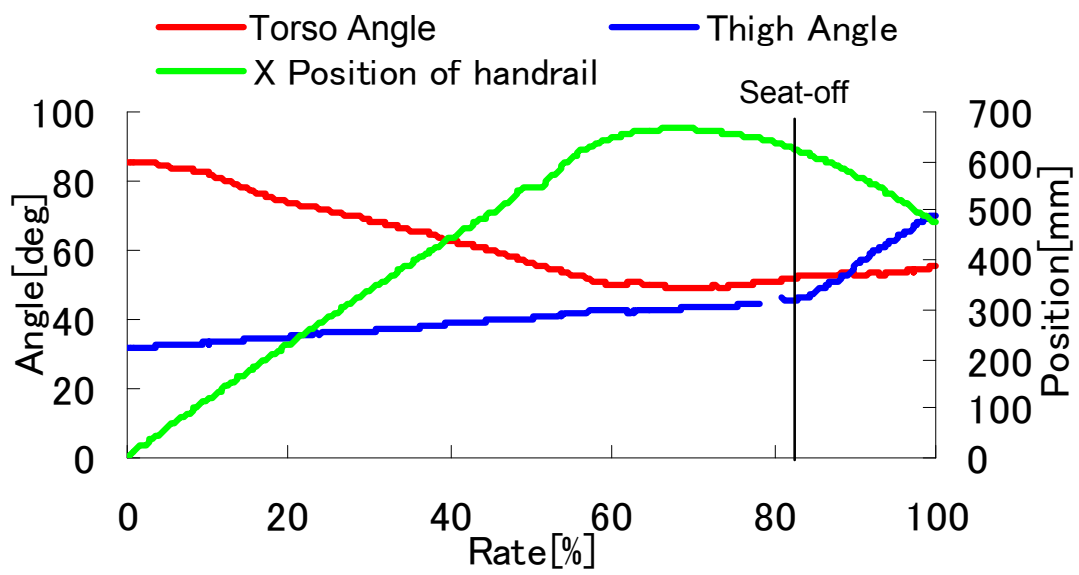

Fig. 13. Torso angle, thigh angle and handrail position of a PD subject at the $70 \%$ threshold 


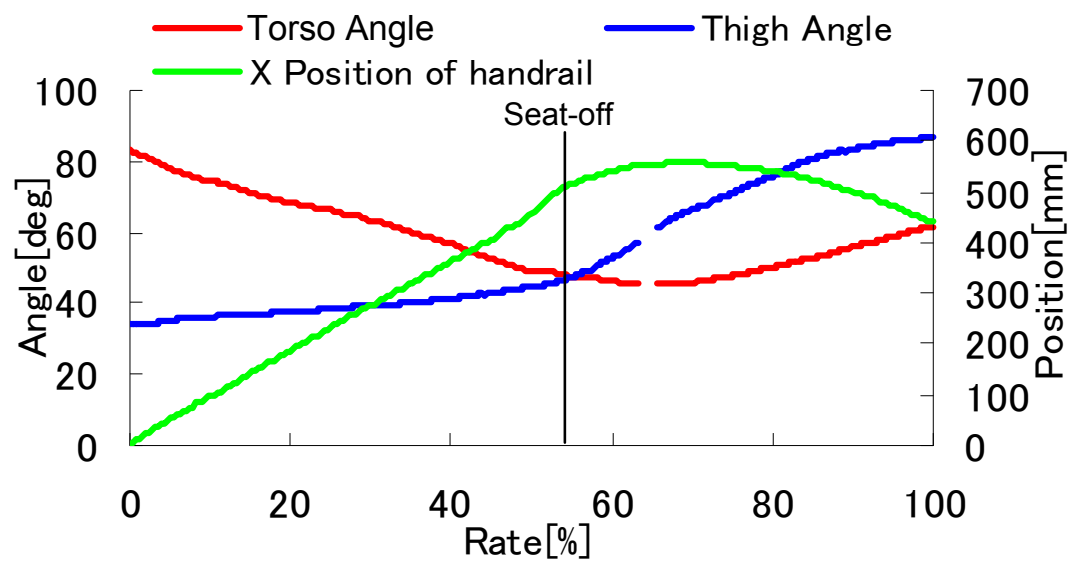

Fig. 14. Torso angle, thigh angle and handrail position of a PD subject at the $80 \%$ threshold

\begin{tabular}{c|c}
\hline Threshold (\% of body weight) & Minimum Trunk Angle [deg] \\
\hline Control (Healthy Subject) & 43 \\
$50 \%$ & 58 \\
$70 \%$ & 47 \\
$80 \%$ & 43 \\
\hline
\end{tabular}

Table 3. Minimum torso angle

\subsection{Knee joint moment}

Figure 15 shows the knee joint moment. Here, it can be seen that the flexion direction is positive and the extension direction has a negative value. This measurement was divided by the subject's height and normalized. The time for sit-to-stand motion was divided by the total time and normalized. Table 4 shows the maximum knee joint moment.

The variation of knee joint moment for healthy test subjects was larger than those measured for PD subjects in extension. At the 50\% threshold, the subject could not achieve seat-off and the variation of the knee joint moment changed only fractionally. At the $70 \%$ and $80 \%$ thresholds, no significant difference was found in the maximum values. However, the timing of peak was different it caused by the different timing of seat-off.

\begin{tabular}{c|c}
\hline Threshold (\% of body weight) & $\begin{array}{c}\text { Maximum Knee Joint Moment } \\
{[\mathrm{Nm} / \mathrm{kg}]}\end{array}$ \\
\hline Control (Healthy Subject) & -1.19 \\
$50 \%$ & -0.26 \\
$70 \%$ & -0.98 \\
$80 \%$ & -0.94 \\
\hline
\end{tabular}

Table 4. Maximum knee joint moment 


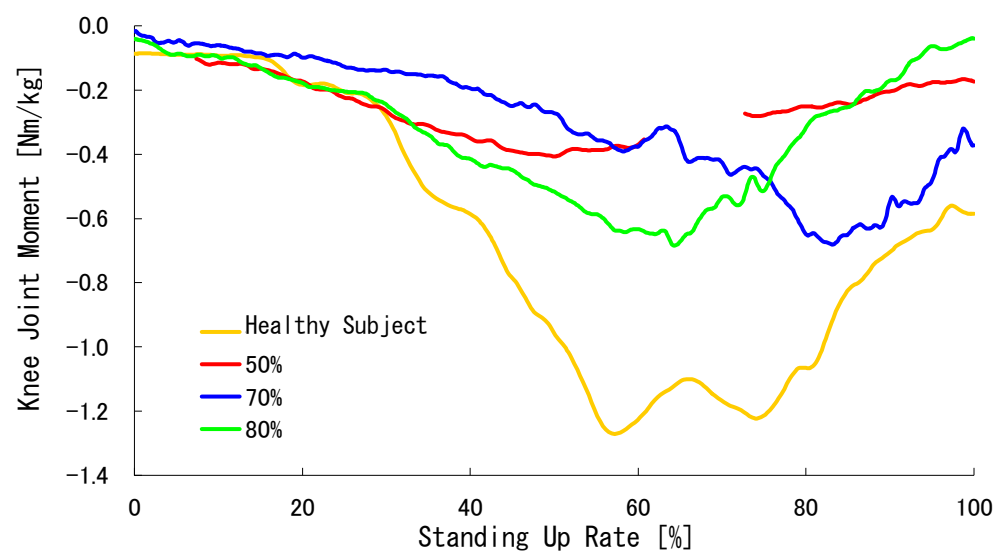

Fig. 15. Knee joint moment

\subsection{Force exerted on the handrail}

Figures 16 and 17 show the force exerted on the handrail on the $X$ and $Y$ axes. Here, the forward and down directions were positive (Figure 4). The $X$ and $Y$ axes of Table 5 and 6 show the maximum force exerted on the handrail.

There were no significant differences between the $50 \%, 70 \%$ and $80 \%$ thresholds on the $X$ axis. However, in the case of the $80 \%$ threshold, the maximum force exerted on the handrail on the $\mathrm{Y}$ axis was less than the $50 \%$ and $70 \%$ thresholds.

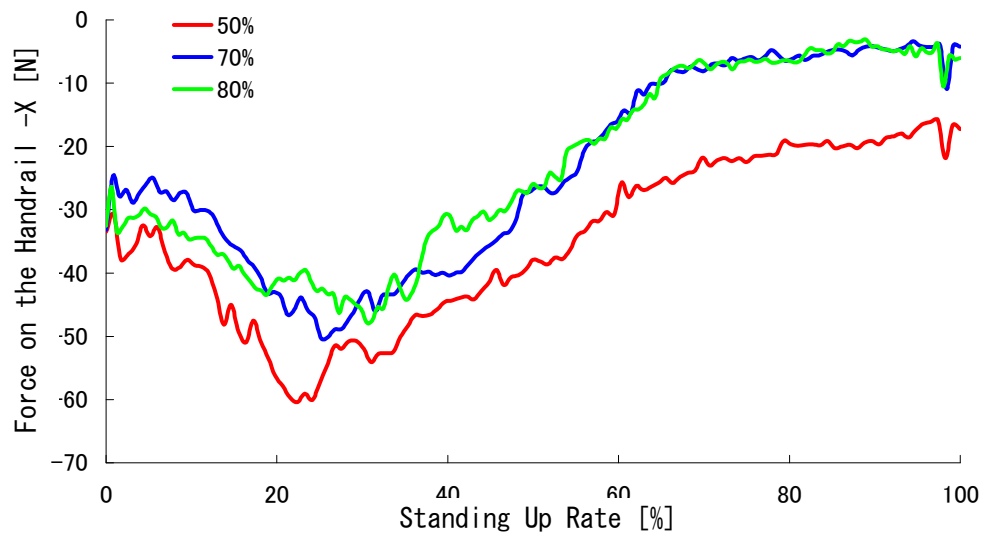

Fig. 16. Force exerted on the handrail as plotted on the $\mathrm{X}$ Axis

\begin{tabular}{c|c}
\hline Threshold (\% of body weight) & $\begin{array}{c}\text { Max. Force on the Hnadrail }-X \\
{[\mathrm{~N}]}\end{array}$ \\
\hline $50 \%$ & -60 \\
$70 \%$ & -65 \\
$80 \%$ & -61 \\
\hline
\end{tabular}

Table 5. Maximum force exerted on the handrail as plotted on the $\mathrm{X}$ axis 


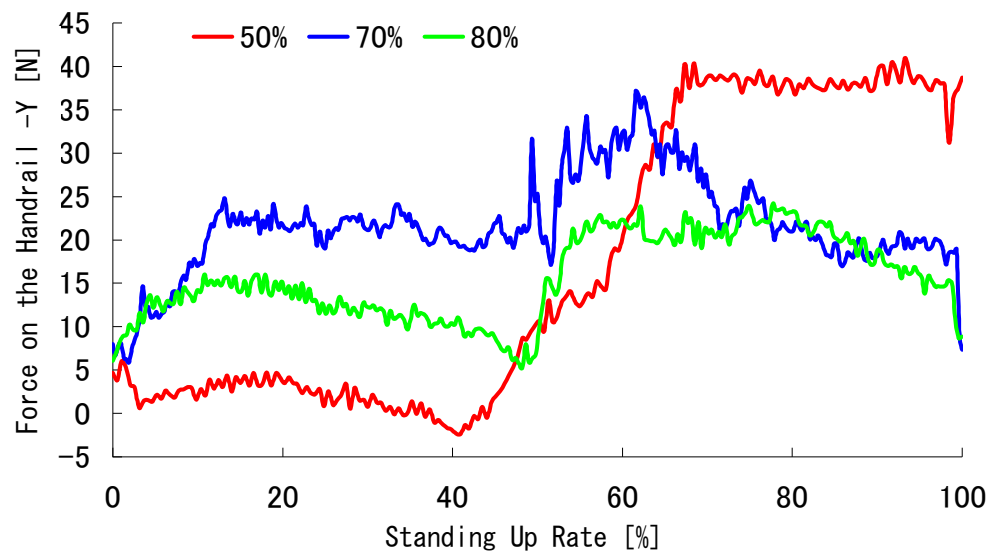

Fig. 17. Force exerted on the handrail on the $Y$ Axis

\begin{tabular}{c|c}
\hline Threshold (\% of body weight) & $\begin{array}{c}\text { Max. Force on the Hnadrail }-\mathrm{Y} \\
{[\mathrm{N}]}\end{array}$ \\
\hline $50 \%$ & 30 \\
$70 \%$ & 32 \\
$80 \%$ & 17 \\
\hline
\end{tabular}

Table 6. Maximum force exerted on the handrail as plotted on the Y Axis

\section{Discussion}

The CG trajectory of a normal healthy test subject increased in a curve after seat-off. At that time, the torso was angled forward. After seat-off, the angle of the torso increased as the subject straightened into a standing posture. The CG was found to have shifted forward a maximum of $54 \%$ of the subjects' foot length, and the knee joint moment was measured at $1.19 \mathrm{Nm} / \mathrm{kg}$ in the extension direction.

The PD test subjects were unable to stand up at the 50\% threshold assistance level. In that situation, the CG shift was $-18 \%$ and the CG did not enter the base of support.

At the $70 \%$ threshold level, the PD test subject was able to stand, but the CG trajectory was different from that of a normal healthy subject, and the timing of the straightening motion was earlier than that for a normal healthy subject. When the handrail started to move backward, the subject's torso angle shifted to vertical. Additionally, it was found that the handrail had moved backward and torso angle had shifted to vertical before seat-off occurred. Thus, it was determined that the CG and posture transition sequence of PD subjects was different from that of normal healthy subjects, and that the PD subjects straightened their torsos before their CG had moved sufficiently forward. They also used stronger downward pushing pressure on the handrail than was exerted at the $80 \%$ threshold.

At the $80 \%$ threshold, PD subjects were able to stand successfully and the CG trajectory was similar to that of a normal healthy subject. It was also determined that PD subjects straightened their torsos after the CG had moved forward onto their base of support. When the subject seat-off occurred, the CG had moved forward approximately $20 \%$ of the subject's foot length and the maximum CG position was $54 \%$ of the foot length. 
These results indicate that moving the handrail forward until the normal force under the feet exceeds $80 \%$ of total body weight, and then actuating the vertical rise of the handrail to perform seat-off could assist PD subjects in performing the sit-to-stand motion in a stable manner.

\section{Conclusions}

A sit-to-stand assistance system was developed and experiments with PD test subjects were performed. The results indicate that a moveable handrail with a forward trajectory ( $\mathrm{X}$ axis) and upward curve motion ( $\mathrm{Y}$ axis) could be used to assist individuals as they transition from a seated to a standing position. The motion direction was actuated by the reaction force exerted on the floor under the feet of the subject, and it was found that the $80 \%$ threshold was the most effective point for initiating assistance to their standing up motion.

\section{Acknowledgment}

I would like to acknowledge the generous support received from Mr. Tomuro, Dr. Takagi and students of the Tokyo Metropolitan University who joined the experiments conducted during this research.

\section{References}

Oshima T., Ito A., Endo Y. (2000). Research of a taste of "diameter and height" of handrail. Proceedings of Architectural Institute of Japan, pp. 1031-1032, ISSN 13414518

Takashima T., Nakanishi Y., Higaki H. (2005). Study of Design of Handrail, Proceedings of the Japan Society of Mechanical Engineers. Proceedings of the Japan Society of Mechanical Engineers, Bioengineering Division, 2005(18), pp. 315-316

Kamnik R., Bajd T., Williamson J., Murray-Smith R. (2005). Rehabilitation Robot Cell for Multimodal Standing-Up Motion Augmentation. Proceedings of the 2005 IEEE International Conference on Robotics and Automation, ICRA 2005, pp. 2277-2282, ISSN 0-7803-8914-X

Chugo D., Okada E., Kawabata K., Kaetsu H., Aasama H., Miyake N. (2005). Force Assistance System for Standing-Up Motion: 1st Report: Required Assistance Power for Standing-Up Motion: 1st Report: Required Assistance Power for Standing-Up. The JSME Symposium on Welfare Engineering Vol.2005(20051207), pp. 257-260

Hoehn M.M, Yarh D. M. (1967). Parkinsonism: onset, progression and mortality. Neurology 17, pp. 427-442

Ichirou H. (2001). Living climate of welfare coordinator second class text, The Tokyo Chamber of Commerce and Industry, ISBN 978-4924547476

Takahashi Y, Osamu N, Komeda T. (2008). Development of a Sit-to-Stand Assistance System. Lecture Notes in Computer Science, 2008, Volume 5105/2008, pp. 1277-1284, ISSN 0302-9743

Uplift Technologies Inc., 17.04.2011, Available from

http:// www.up-lift.com/

TOTO LTD., 17.04.2011, Available from

http:// www.toto.co.jp/ 


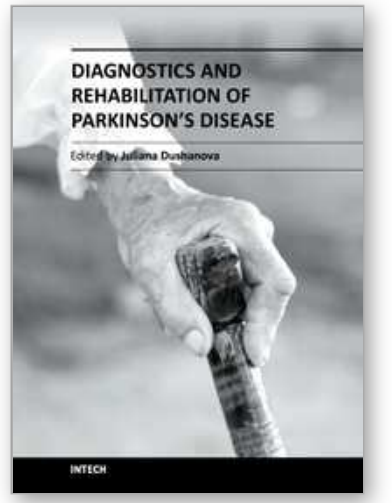

\author{
Diagnostics and Rehabilitation of Parkinson's Disease \\ Edited by Dr. Juliana Dushanova
}

ISBN 978-953-307-791-8

Hard cover, 528 pages

Publisher InTech

Published online 07, December, 2011

Published in print edition December, 2011

Diagnostics and Rehabilitation of Parkinson's Disease presents the most current information pertaining to news-making topics relating to this disease, including etiology, early biomarkers for the diagnostics, novel methods to evaluate symptoms, research, multidisciplinary rehabilitation, new applications of brain imaging and invasive methods to the study of Parkinson's disease. Researchers have only recently begun to focus on the non-motor symptoms of Parkinson's disease, which are poorly recognized and inadequately treated by clinicians. The non-motor symptoms of Parkinson's disease have a significant impact on patient quality of life and mortality and include cognitive impairments, autonomic, gastrointestinal, and sensory symptoms. In-depth discussion of the use of imaging tools to study disease mechanisms is also provided, with emphasis on the abnormal network organization in parkinsonism. Deep brain stimulation management is a paradigm-shifting therapy for Parkinson's disease, essential tremor, and dystonia. In the recent years, new approaches of early diagnostics, training programmes and treatments have vastly improved the lives of people with Parkinson's disease, substantially reducing symptoms and significantly delaying disability. Written by leading scientists on movement and neurological disorders, this comprehensive book should appeal to a multidisciplinary audience and help people cope with medical, emotional, and practical challenges.

\title{
How to reference
}

In order to correctly reference this scholarly work, feel free to copy and paste the following:

Yoshiyuki Takahashi, Osamu Nitta and Takashi Komeda (2011). Improving Transfer of Parkinson's Disease Patients - Sit-to-Stand Motion Assistance, Diagnostics and Rehabilitation of Parkinson's Disease, Dr. Juliana Dushanova (Ed.), ISBN: 978-953-307-791-8, InTech, Available from:

http://www.intechopen.com/books/diagnostics-and-rehabilitation-of-parkinson-s-disease/improving-transfer-ofparkinson-s-disease-patients-sit-to-stand-motion-assistance

\section{INTECH}

open science | open minds

\section{InTech Europe}

University Campus STeP Ri

Slavka Krautzeka 83/A

51000 Rijeka, Croatia

Phone: +385 (51) 770447

Fax: +385 (51) 686166

\section{InTech China}

Unit 405, Office Block, Hotel Equatorial Shanghai

No.65, Yan An Road (West), Shanghai, 200040, China 中国上海市延安西路65号上海国际贵都大饭店办公楼 405 单元

Phone: +86-21-62489820

Fax: +86-21-62489821 
www.intechopen.com 
(C) 2011 The Author(s). Licensee IntechOpen. This is an open access article distributed under the terms of the Creative Commons Attribution 3.0 License, which permits unrestricted use, distribution, and reproduction in any medium, provided the original work is properly cited. 